WellBeing International

WBI Studies Repository

2015

\title{
The Medicalization of Nonhuman Animal Rights: Frame Contestation and the Exploitation of Disability
}

\author{
Corey Lee Wrenn \\ Colorado State University, corey.wrenn@gmail.com \\ Joanne Clark \\ Independent Coder \\ Maddie Judge \\ University of Melbourne \\ Katherine A. Gilchrist \\ Independent Coder \\ Delanie Woodlock \\ Independent Coder
}

See next page for additional authors

Follow this and additional works at: https://www.wellbeingintlstudiesrepository.org/anirmov

Part of the Animal Studies Commons, Civic and Community Engagement Commons, and the Politics and Social Change Commons

\section{Recommended Citation}

Wrenn, C. L., Clark, J., Judge, M., Gilchrist, K. A., Woodlock, D., Dotson, K., ... \& Wrenn, J. (2015). The medicalization of Nonhuman Animal rights: frame contestation and the exploitation of disability. Disability \& Society, 30(9), 1307-1327.

This material is brought to you for free and open access by WellBeing International. It has been accepted for inclusion by an authorized administrator of the WBI Studies Repository. For more information, please contact wbisr-info@wellbeingintl.org.

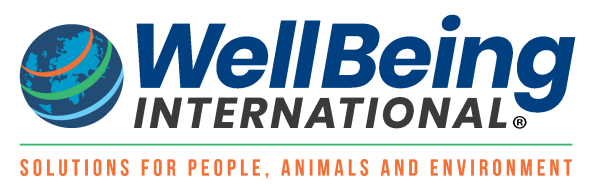




\section{Authors}

Corey Lee Wrenn, Joanne Clark, Maddie Judge, Katherine A. Gilchrist, Delanie Woodlock, Katherine Dotson, Riva Spanos, and Jonothan Wrenn 


\title{
The Medicalization of Nonhuman Animal Rights: Frame Contestation and the Exploitation of Disability
}

Corey Lee Wrenn ${ }^{\mathrm{a}}$, Joanne Clark ${ }^{\mathrm{b}}$, Maddie Judge ${ }^{\mathrm{c}}$, Katharine A. Gilchrist ${ }^{\mathrm{d}}$, Delanie Woodlock ${ }^{\mathrm{e}}$, Katherine Dotson $^{f}$, Riva Spanos ${ }^{g}$ and Jonothan Wrenn ${ }^{h}$

${ }^{\text {a }}$ Colorado State University - Fort Collins

${ }^{\mathrm{b}}$ Independent Coder - USA

${ }^{\mathrm{c}}$ University of Melbourne

d Independent Coder - UK

${ }^{\mathrm{e}}$ Independent Coder - Collingwood, VIC, Australia

${ }^{f}$ Rutgers University

${ }^{\mathrm{g}}$ Independent Coder - Lincoln, NH, USA

${ }^{\mathrm{h}}$ Virginia Commonwealth University

\section{KEYWORDS}

ableism, animal rights, frames, identity, medicalization, social movements

\begin{abstract}
Nonhuman Animal rights activists are sometimes dismissed as 'crazy' or irrational by countermovements seeking to protect status quo social structures. Social movements themselves often utilize disability narratives in their claims-making as well. In this article, we argue that Nonhuman Animal exploitation and Nonhuman Animal rights activism are sometimes medicalized in frame disputes. The contestation over mental ability ultimately exploits humans with disabilities. The medicalization of Nonhuman Animal rights activism diminishes activists' social justice claims, but the movement's medicalization of Nonhuman Animal use unfairly otherizes its target population and treats disability identity as a pejorative. Utilizing a content analysis of major newspapers and anti-speciesist activist blogs published between 2009 and 2013, it is argued that disability has been incorporated into the tactical repertoires of the Nonhuman Animal rights movement and countermovements, becoming a site of frame contestation. The findings could have implications for a number of other social movements that also negatively utilize disability narratives.
\end{abstract}

\section{POINTS OF INTEREST}

- Throughout history, social justice activism has been medicalized with activists labeled as mentally ill to dismiss their claims.

- This study focuses on the Nonhuman Animal rights movement and found that activists are often labeled as mentally ill by elite-run mainstream media sources.

- The research found that activists also utilize ableism in order to frame discrimination against Nonhuman Animals as mental illness. 
- Both social movements and countermovements utilize negative stereotypes about disability in order to frame their argument in hopes of improving resonance and support.

- For social justice movements, the utilization of ableism is predicted to be a counterproductive and ethically problematic strategy which decreases a movement's credibility and ability to build alliances.

\section{Introduction}

Medicalization refers to the process of symbolically transforming a relatively normal or common human characteristic into one that is deviant, cause for concern, and potentially in need of medical intervention (Conrad 2007). For example, menopause, a normal occurrence for cis-gender women, has been medicalized as a problem in need of hormone replacement therapy (Meyer 2001). It has also been suggested that the rising levels of attention-deficit hyperactivity disorder diagnoses reflect the medicalization of socialization-resistant boys (Hart, Grand, and Riley 2006; Searight and McLaren 1998). This phenomenon is indicative of how health is largely socially constructed (Yadavendu 2001). While some health issues are objectively real and may require some level of care and coping, other issues are merely in the eye of the beholder. According to the Thomas Theorem, when a mental illness is defined as real, the consequences of that defined reality are real indeed (Link et al. 1999). Thus, the social construction of health bears important ramifications. In this article, we discuss how the Nonhuman Animal $^{1}$ rights movement has used frameworks of medicalization to achieve its goals and police its membership. While this is fundamentally a case study in anti-speciesist mobilization, it will have implications for a number of other movements as well. Countermovements often medicalize activism on behalf of other animals as a mental illness, yet the movement to liberate other animals also utilizes the rhetoric of disability. Those who engage in Nonhuman Animal exploitation are often labeled 'sick,' and even radical activists within the movement itself are subject to similar labels.

Medicalization tends to be a means of control that reinforces the status of the privileged while disempowering groups living under institutional discrimination (Conrad 1992; Link et al. 1999; Schur 1984). If a group can be successfully framed as physically or mentally 'inferior,' that group can be effectively silenced in order to maintain an unequal or oppressive social hierarchy. Foucault (1965) has argued that 'madness' is a social construction used to otherize, marginalize, institutionalize, and exploit undesirables. Social Darwinism and scientific racism of the late nineteenth and early twentieth centuries, for instance, justified racial inequality in suggesting that African Americans were biologically inferior and not suited for full rights (Dennis 1995). Women, too, have long been denied equal opportunities based on their supposed physical and mental deficiencies (Reed 1978; Schur 1984). Likewise, homosexuality was classified as a mental disorder by the American Psychiatric Association until 1973, thus legitimizing any number of medical 'interventions' on homosexual patients (Mayes and Horwitz 2005).

Medicalization has been a powerful tool of social control, and this control, we argue, extends into the social movement arena. Those who stand to lose privilege and other benefits can diminish a social movement's threat by medicalizing that movement's claims. For instance, feminists were (and continue to be) labeled hysterical (Gilman et al. 1993; Mitchel 2004). In some regions, African American Civil Rights protestors of the 1960s and 1970s were routinely diagnosed with schizophrenia and institutionalized 
(Metzl 2010). More recently, both sides of the debate over gun control tend to pin gun violence on the mentally ill (Friedman 2012; Hinshaw 2007). Alternatively, social movements might also use disability narratives to frame their targeted social problem. This could be a crass reaction to frustration over the sluggishness of social change, or it could act as a means to shame their audience into compliance. It might also be part of a strategy to protect their group identity. In constructing what their movement is, for instance, Nonhuman Animal rights activists work to define what they are not (Einwohner 2002). In effect, they seek to otherize the opposition (Maurer 2002).

Caught in the middle of this frame contestation, however, are those individuals who really do live with the stigma attached to mental health conditions and learning impairments. As a group, people with disabilities have experienced extreme social stigmatization and discrimination (Corrigan 2000). This stigmatization is not only emotionally hurtful, but can interfere with access to health care when individuals avoid services out of embarrassment or shame (Corrigan 2004).

Mitchell and Snyder (2000) have argued that the use of disability in narratives acts as a sort of 'prosthesis' in the story to illustrate an able-bodied norm that is idealized. That is, disability is often understood to represent moral or physical failure, and is therefore included in a story to describe, achieve, or enforce the desired 'normal' society. In this way, people with disabilities become simultaneously objects of resource and devalued metaphorical points of comparison. Mitchell and Synder would probably understand narrative prosthesis in social movement claims-making as a 'crutch' in mobilization discourse. Social movements and countermovements identify disability in the opponent as a plot device to tell a story about the social world they envision. When disability identity becomes a tool in the repertoire that is designed to demean and dismiss opponents in the social movement arena, the discrimination experienced by people with disabilities is reinforced and aggravated. While ableism in any form is problematic, a social movement that is based in social justice should be particularly wary of how politicizing mental disability can otherize and injure oppressed populations.

\section{Frame contestation}

Social movements battle with hegemonic ideologies and institutions for the right to construct meaning and frame a given social problem (Benford 1993; Benford and Snow 2000; Zald 1996). Culture is a powerful influence on the beliefs and behaviors of individuals and groups; therefore, social movements expend considerable effort in attempting to manipulate it (Swidler 1995). While social movements attempt to shape culture, they are ultimately products of that culture as well (McAdam 1994). Framing efforts also reflect prevailing ideologies (Oliver and Johnston 2000; Westby 2002). While it is true that the United States has spawned considerable disability activism and now recognizes a number of civil rights for people with disabilities (Shapiro 1994), American society remains deeply ableist (Hinshaw 2007). It is also a society with a fierce commitment to capitalism, an inherently oppressive economic system that requires strong ideological support for routinized exploitation and exaggerated social inequality (Nibert 2002). If ableism and exploitation are characteristically American, and a movement's claims-making is embedded in a society's culture and ideology, this embeddedness is likely to be on some level responsible for the exploitation of disability stigmatization in social movement activity. The Nonhuman Animal rights movement is one based on social justice and equality, but it continues to reflect discrimination against the disability community. To successfully manipulate meaning and find audience for its claims-making, a social movement must create a resonant frame to which an audience can relate (Benford and Snow 2000; Snow and Corrigall-Brown 2005). Unfortunately, it appears that embedding claims in the normalized stigmatization of persons with disabilities is considered effective framing.

Frame resonance is vital to social movement success. For this reason, drawing on social norms is to be expected. For example, the Asamblea de Barrios movement in Mexico promoted a masked 'Superbarrio' 
hero character that drew on Mexico's wrestling culture. The Superbarrio symbol utilized dramaturgy and whipped up fevered emotions to motivate collective action against corporate exploitation (Cadena-Roa 2002). American anti-slavery abolitionists also sought to legitimate their activism through the manipulation of meaning. They achieved this by aligning their cause with the popular American values of law and order (which put anti-abolitionist mob violence in a bad light) (Ellingson 1995; Grimsted 1998) and the language of democracy and natural rights (Mason 2011). Of course, not all prevailing cultural norms are positive. A movement's mobilizing structure is ultimately embedded within the larger society, thus limiting tactical decision-making to some extent (Clemens 1996). It is possible that social movements are also dipping into prevailing prejudices and unexamined inequality to ground their claims-making and equip their action repertoires.

\section{Ableism in Nonhuman Animal rights movement claims-making}

In a 2010 blog post, People for the Ethical Treatment of Animals (PETA) suggests that consuming the flesh of other animals is on a par with sociopathy (Goldstein 2010). Drawing support from a psychotherapist guest blogger, PETA claims the 'professional view' is that 'only sociopaths intentionally hurt animals [...]' (Pruitt 2010). More recently, a health textbook distributed to students in India claimed that non-vegetarians were apt to cheat, lie, forget promises, fight, and commit violence and sexual assault (BBC News India 2012). Writing for The Guardian, columnist Barbara Ellen (2012) refers to 'meat' ${ }^{2}$ eaters as 'dumb,' because: '[...] people who've been regularly informed of the dangers of meat [...] but who continue to wolf it down should be held [...] accountable.'

The exploitation and killing of other animals is behavior that, for the most part, is normalized and socially acceptable (Joy 2010). However, Nonhuman Animal rights activists (and Indian elites in an increasingly carnivorous India) reframe this consumption as sociopathic deviancy or idiocy. Pejoratives relating to intellectual ability and mental health become tactics for social change and movement recruitment. Meanwhile, those who identify as disabled and those suffering the stigma of disability become the absent referent: ${ }^{3}$ disability identity becomes politicized for social movement repertories, but those living with impairments in an ableist society tend to be ignored in the claims-making process. This process effectively objectifies people with disabilities.

Theorists in the anti-speciesist community also pull on ableist claims-making. Ethicist Peter Singer, for instance, engages in what Salomon (2010) calls 'neurotypicality' in his analysis of human/nonhuman relationships. Singer suggests that the existence of cognitive impairment challenges the value we place on human life (and subsequently nonhuman life), and proposes a 'graduated view of the moral status of humans and nonhuman animals' $(2009,568)$. In doing so, he normalizes a particular cognitive ability, one that is enjoyed by non-disabled persons. This privileged variation of cognitive ability remains unexamined as superior and preferable. Those with mental health conditions and learning difficulties can be ascribed a lower status and might be granted less moral standing.

In another example, rights theorist Gary Francione (2008) describes our contradicting attitudes towards other animals as 'moral schizophrenia.' He explains that the majority of Americans reject the imposition of unnecessary harm on other animals, while the majority also regularly imposes unnecessary suffering on other animals in continuing to eat, wear, and otherwise exploit them. The phenomenon Francione describes is a widely experienced psychological condition known as cognitive dissonance (a discomforting misalignment between attitudes and actions). In labeling it 'schizophrenic,' he effectively exploits the stigmatization of mental illness in order to demean his audience and presumably recruit new participants. It should be noted that schizophrenia is one of the most stigmatizing mental health labels. The stigma associated with schizophrenia can disable and diminish the life chances and quality of life for many individuals and their families (Schulze and Angermeyer 2003). 
Central to these ableist social movement claims is the presumption of agency and responsibility for one's mental state and actions. Activists using disability narratives seem to imply that individuals should have the means to realize that Nonhuman Animal exploitation is morally problematic or hazardous to their health, and should they fail to do so they are 'dumb' or 'schizophrenic' to their own detriment. From a sociological perspective, individuals can hardly be held completely responsible for deconstructing banal, taken-for-granted social practices. Speciesism and other forms of oppression are, for all intents and purposes, hidden from view, and ideologies and institutions work to legitimize, normalize, and entrench that oppression (Nibert 2002). Speciesism, then, goes for the most part unexamined. While many do manage to overcome oppressive socialization processes, most do not, and the reasons for this discrepancy are infinitely complex (Oegema and Klandermans 1994; Wrenn 2015). Thus, while personal responsibility in the face of injustice and oppression is certainly important, 'blaming' the public for nonconversion is not entirely appropriate.

Blaming those who deviate from accepted social behavior has implications for mental health as well. Oftentimes, people with disabilities are held personally responsible for their impairments or disability status. Blaming, as often happens to individuals with obsessive compulsive disorder (Rachman et al. 1995), for example, fails to take into account outside forces that have contributed to the individual's social position or physical condition. Indeed, as often as mentally impaired persons are thought to be unable to control themselves and are stripped of their agency, they are just as often considered personally responsible for their condition and for seeking treatment (Abramson and Sackheim 1977). People with disabilities, like anyone else, are primarily influenced by environmental and genetic factors. In a similar vein, social movement targets are not 'dumb' people who ignore the facts. They are more often than not well-socialized individuals who are products of a self-reproducing and efficiently oppressive society. Recognizing the influence of outside factors does not mean that mental impairment is unimportant or nonexistent, and neither does it mean that non-vegans are incapable of change. It simply means that an individualist focus on personal culpability does not show us the whole picture.

\section{Ableism as a countermovement tactic}

Industries that exploit Nonhuman Animals and individuals who benefit from that exploitation have mounted a strong opposition to the Nonhuman Animal rights movement (Munro 1999). Countermovements tend to spring up in response to increased social movement influence (Andrews 2002; Mottl 1980). To protect the threatened status quo that has traditionally advantaged it, a countermovement will engage in frame contestation with the social movement for the right to construct a reality that favors its interests. The media - communication channels such as newspapers, radio, television, books, magazines, and the Internet - are one site of this struggle. Here, social movements and their opponents combat for coverage and legitimacy (Gamson and Modigliani 1989). Although media are unevenly absorbed and interpreted differently across individuals and groups, the media are nonetheless an ideological tool of the powerful. For this reason, social movements may have difficulty wielding media effectively and countermovements can enjoy an edge (Gamson et al. 1992). Influencing public opinion through media discourse has been particularly difficult for the Nonhuman Animal rights movement. Cole and Morgan (2011) have suggested that consistently negative portrayals of veganism in the media protect and reproduce the countermovement's hegemony, thus stunting Nonhuman Animal liberation efforts by silencing their claims-making. Tom Regan, a leading anti-speciesist activist and philosopher, also insists that this negative image is one of the primary barriers to successful mobilization: 'Many people view ARAs [animal rights activists] as certifiable, grade-A, top of the class nut cases' (Regan n.d.). He points to speciesist industries and their financial control over the media as a primary source of misinformation regarding activism on behalf of other animals (Regan 2004a). 


\section{Ableism against anti-speciesism}

Examples of ableist counterclaims-making against Nonhuman Animal rights activists abound, perhaps acting as one of the most prominent tropes. The Economist (1995) has labeled Nonhuman Animal liberationists 'loopy.' A Michigan newspaper interviewed celebrity zoo operator Jack Hanna, who stated that activists were 'just plain nutcases' (Crowell 2010). A BBC travel correspondent referred to vegetarianism as an 'exotic illness' (Mitzman 2013). Jezebel, a women's news and fashion site known to promote 'fur' consumption, has stated that 'Animal rights activists have been known to do some pretty crazy stuff [...]' (Murdoch 2012). ${ }^{4}$ There are even Facebook groups titled 'The DSM V Needs to Classify Animal Rights Activism as a Mental Disorder' ${ }^{5}$ and 'Animal Rights Activists with Mental Disorders', ${ }^{6}$ where the administrators regularly post news items on Nonhuman Animal activism, presenting them as evidence for psychiatric illness.

Some of this ableism may be due to the fact that as much as $80 \%$ of the Nonhuman Animal rights movement identifies as female (Gaarder 2011). As Munro (2005) explains, women's 'emotionality' is often used as a reason to dismiss claims on behalf of Nonhuman Animals: 'Stereotypes associated with labels such as "sob sisters", "crazed spinsters" and "idle, muddle-headed women" continue to be used against the "emotional" arguments of women in the movement who oppose the "rational", mainly male endeavors of science, hunting and agriculture' $(2005,66)$. Indeed, hunting apologist James Swan targets feminism in the Nonhuman Animal rights movement, suggesting that activists are:

[...] emotionally immature and are acting out repressed rage and hatred from emotional wounds from parental abuse or from failed love affairs, seeing the plight of 'defenseless animals' as symbolically similar to how they may feel they have been personally treated by a dominating human [...]. (Swan 1995, 188)

He even suspects that vegetarianism is an '[...] early symptom of guilt-driven suicide' $(1995,188)$.

In some cases, the influence of this ableist countermovement strategy can go so far as to impede on constitutional rights. In 2012, the state of New Jersey insisted that a woman with a history of nonviolent Nonhuman Animal rights activism ${ }^{7}$ should be denied a firearms purchaser identification card unless she was to undergo a mental health evaluation (Moszczynski 2012). While the defendant was requesting the card in order to transport her deceased partner's firearm collection, the state claimed that she was a 'safety issue' and that carrying a firearm 'could be a problem for her.'

\section{Ableism in the ranks}

Countermovements have been able to manipulate the media and the state to advance their framing interests by enacting ableist terminology. However, ableist counter-framing exists within the Nonhuman Animal movement as well. PETA, an organization that seeks to improve the welfare of other animals (many times in ways that run counter to liberation), ${ }^{8}$ regularly campaigns against what it understands to be Nonhuman Animal hoarding (PETA 2005). According to its definition, a hoarder is anyone who amasses a large number of Nonhuman Animals (the number is unspecified), fails to maintain the health of those Nonhuman Animals, and denies them adequate conditions. This definition is relatively subjective, and PETA reiterates that '[...] hoarding knows no boundaries [...]' $(2005,2)$. It is often applied to No Kill shelters as part of its ongoing anti-No Kill campaign (a probable reaction to the No Kill movement's criticism of PETA's 95\% kill rate) (Winograd 2007). Thus, No Kill shelters are often conflated with hoarding situations (PETA n.d., 2010). While there are certainly real cases of Nonhuman Animal hoarding that seriously jeopardize the health of those animals involved, PETA's exploitation of a heavily stigmatized mental health issue in its counterclaims-making is deeply problematic. Hoarding is a mental 
health concern that goes beyond the labeled individual to affect their family and community as well (Frost, Steketee, and Williams 2001; Patronek 1999). Reconstructing Nonhuman Animal rights efforts as hoarding not only dismisses liberation efforts, but diminishes the lived reality of those who hoard (or are thought to hoard) in a debilitating or harmful manner. ${ }^{9}$

\section{Methodology}

The data for this analysis were collected from two sources: major English-language newspaper publications, and popular blogs on veganism and Nonhuman Animal rights. A study conducted by BMC Health Services Research identified 250 labels used to stigmatize people with mental illness (Rose et al. 2007). The researchers identified 44 labels that were most commonly used, and these terms were used to guide our project. ${ }^{10}$ Some terms were removed because their character sequence was associated with a large number of unrelated words, and this created too many unrelated results (such as div, ill, and mad). Another term, 'loony bin,' was removed because it pulled the same results as another keyword, 'loony.' This left us with 32 terms.

It has been documented that mainstream media is a powerful source of meaning construction that most often depicts veganism and Nonhuman Animal rights activism negatively (Blaxter 2009; Cole and Morgan 2011; Freeman 2009; Morgan and Cole 2011). The media also acts to reflect state, elite, and industry interests (Croteau and Hoynes 2003), making it suitable for analyzing mental illness frames for activists. To determine how veganism and Nonhuman Animal rights is popularly framed, we conducted a LexisNexis search for a five-year span (2009-fall 2013) in major world news publications for keywords 'animal rights,' 'animal lover,' 'animal liberation,' 'animal extremist,' 'animal terrorist,' 'vegan,' 'vegetarian,' and 'veggie.' ${ }^{11}$ Headlines that appeared more than once in different newspapers were coded individually for each appearance. This search was narrowed with a headline search for each of the 32 disability labels. A headline was coded as ableist if the ableist keyword in the headline related directly to Nonhuman Animal activism in the corresponding story. For example, The Telegraph published a story under the headline: 'Natalie Portman Reinforces Stereotypes about Loony Veggies by "Equating Meateating with Rape"' (Jones 2009). Likewise, a story about anti-'fur' protesting published by The Sun under the headline 'Fur Nuts Threaten Barnardo' (Breen 2011) was also coded as ableist.

To determine the presence of ableist claims-making made by Nonhuman Animal rights activists, we located $51^{12}$ top blogs from The Vegan Feed, '[...] a website dedicated to discovering and sharing vegan media [...]. ${ }^{, 13}$ Blog content varies from food and nutrition to movement theory and ethics. Using the search functions on each blog, we accessed entries posted within a five-year span (2009-2013) that contained our chosen mental illness labels. ${ }^{14}$ Entries were only included if the label was applied to nonvegans, 'animal abusers,' and so forth, as part of a claims-making mechanism.

\section{Limitations}

One weakness in our methodology is that our list of ableist keywords derives from a study of school-age children's descriptions of mental illness. Because the authors of newspaper and blog pieces are presumed to be adult, schoolchildren vernacular may not be representative. Some terms like 'flid' are also uniquely British and did not offer many results, if any at all. In limiting our search to 32 terms, our list is not at all exhaustive and many other relevant terms like 'evil' and 'sadist' were necessarily excluded. We chose to adhere to the short list of keywords to keep the project at a manageable size, particularly because keyword searches had to be done manually in vegan blogs. The BMC Health Services list provides some variations on the same root word to improve results (e.g. 'depressed' and 'depression'), but others were not expanded (e.g. 'violence'). This means that some relevant data may have been overlooked (bloggers that referred to exploiters as 'violent,' for example). 
Another issue arose with interpretation and context. Many terms like 'crazy' and 'different' are heavily utilized in everyday language. Although cases that do not use these mental illness terms in relation to Nonhuman Animal activists or exploiters were omitted from the content analysis, we found it interesting that many bloggers take considerable liberty with ableist language in non-derogatory contexts. Many food bloggers, as an example, describe their recipes as 'crazy good' or 'insanely delicious.' Many terms included in the sample are rarely used in an overtly discriminatory way by authors. By way of another example, bloggers might refer to 'different eating styles' (Hamshaw 2011), but are not implying that those who consume non-vegan diets are 'different.' Therefore, the nuance of language proved critical in decoding Nonhuman Animal rights discourse.

Of those keywords in our sample that are used in a derogatory way, interpretation continues to be difficult because the social justice discourse involving the oppression of other animals utilizes words that can be interpreted in multiple ways. For instance, 'violence' (an outlier in our vegan blog results) appears to be applied in a potentially ableist manner 173 times. Often, this word is used to describe the character and behavior of those involved in Nonhuman Animal exploitation. The nature of Nonhuman Animal exploitation, however, inherently involves considerable violence, especially for those animals that are experimented on or killed for food. Likewise, 'problem' appears 70 times in our sample, and the interpretation is muddied by the fact that the Nonhuman Animal rights movement frames speciesism as a 'problem.' In both of these cases, these terms were coded only when they specifically referred to human disposition (either in reference to an individual human or humans as a group).

Another point of contention relates to the difficulty in building comparisons between our two samples. Because our newspaper sample contains a very large amount of information (probably thousands of newspapers and hundreds of thousands of stories), we analyzed only the headlines. Our vegan blog sample, however, is much smaller and contains very few data in comparison with the newspaper sample, meaning that focusing only on blog headlines would not provide adequate data. Therefore, this study relies on a comparison between newspaper headlines (in reference to, but not including, corresponding story content) and blog content (in addition to corresponding headlines). A more thorough analysis might explore the content of the newspaper story as well as the headline, and may be fruitful for future research.

\section{Findings}

Newspaper anti-speciesism countermovement discourse

As predicted, mainstream news sources in our sample often frame Nonhuman Animal rights issues negatively through the use of ableist language (Table 1). This finding is consistent with observations previously reported by Cole and Morgan (2011), Freeman (2009), and others regarding the overall negative representation of anti-speciesism activism in the media. LexisNexis utilizes a large (and undefined) number of newspaper sources with varying publication frequencies. This made calculating percentages of occurrences impossible. Within the five-year sample of major newspaper headlines, ableist words were used to describe Nonhuman Animal activism a total of 229 times. This compares with 537 occurrences in the content of 50 vegan blogs within the same time frame. ${ }^{15}$

\section{Anti-speciesism social movement discourse}

Vegan blogs in our sample also utilize ableist language (Table 2; Figure 1). For many blogs, we were able to determine the frequency average based on the number of entries published in our five-year sample. Eight blogs do not have a website design that facilitated any ability to calculate the total number of posts. ${ }^{16}$ For one of our outliers, Animal Rights: The Abolitionist Approach, there are 319 entries included 
in the sample. With 323 ableist terms identified in this blog's sample, this blog averages slightly more than one ableist word per entry. Co-occurrence of disability variables would indicate stronger evidence of potential ableism, but very few of these relationships appear in our blog data. The only two variables with any significant degree of co-occurrence ('schizophrenia' and 'confused') appear in the blog, Animal Rights: The Abolitionist Approach. The blog's author insists that the use of 'schizophrenia' in reference to Nonhuman Animal exploitation is not intended to draw on the stigma of mental illness (Francione 2009), although our sampling results indicate that the author's intention may be lost on the blog's audience.

Table 1. Newspaper headline frequencies.

\begin{tabular}{|c|c|c|}
\hline Term & Frequency & Percentage \\
\hline Brain dead & 0 & 0 \\
\hline Confused & 3 & 1.7 \\
\hline Crazy & 27 & 15.6 \\
\hline Demented & 0 & 0.0 \\
\hline Depressed & 2 & 1.2 \\
\hline Depression & 2 & 1.2 \\
\hline Different & 18 & 10.4 \\
\hline Distressed & 0 & 0.0 \\
\hline Disturbed & 1 & 0.6 \\
\hline Dumb & 1 & 0.6 \\
\hline Embarrassed & 11 & 6.4 \\
\hline Flid & 0 & 0.0 \\
\hline Freak & 12 & 6.9 \\
\hline Frustrated & 0 & 0.0 \\
\hline Insane & 1 & 0.6 \\
\hline Isolated & 3 & 1.7 \\
\hline Loneliness & 1 & 0.6 \\
\hline Loony & 10 & 5.8 \\
\hline Mental & 6 & 3.5 \\
\hline Nuts & 35 & 20.2 \\
\hline Problem & 20 & 11.6 \\
\hline Psychiatric & 0 & 0.0 \\
\hline Psycho & 1 & 0.6 \\
\hline Retard & 0 & 0.0 \\
\hline Sad & 8 & 4.6 \\
\hline Schizophrenia & 3 & 1.7 \\
\hline Screw loose & 0 & 0.0 \\
\hline Spastic & 0 & 0.0 \\
\hline Straight jacket & 0 & 0.0 \\
\hline Unpredictable & 0 & 0.0 \\
\hline Violence & 8 & 4.6 \\
\hline Wheel chairs & 0 & 0.0 \\
\hline Total & 173 & 100.0 \\
\hline
\end{tabular}

We were also able to determine which types of blogs were more likely to utilize ableist rhetoric. Blogs were divided into three groups: non-profit affiliated $(n=9 ; 18 \%) ;{ }^{17}$ theory/unaffiliated $(n=11 ; 22 \%)$; and consumption, food, or nutrition $(n=29 ; 58 \%)$. Three levels of potential ableism were also identified. Blogs that have a keyword frequency between zero and 11 were labeled 'not ableist' ( $n=38 ; 76 \%)$, blogs with a keyword frequency between 12 and 22 were labeled 'ableist,' and blogs with a frequency between 22 and 
33 or more were labeled 'very ableist' in comparison with other blogs in the sample $(n=5 ; 10 \%)$ (Table 3 ). Overall, only $24 \%$ of the sample blogs contain enough material to be considered especially ableist, accounting for two-thirds of the total ableist rhetoric coded (14\% of blogs were coded as 'ableist' and $10 \%$ of blogs were coded as 'very ableist') (Figure 2).

Table 2. Vegan blog frequencies.

\begin{tabular}{|c|c|c|}
\hline Term & Frequency & Percentage \\
\hline Brain dead & 1 & 0.2 \\
\hline Confused & 6 & 1.2 \\
\hline Crazy & 31 & 6.4 \\
\hline Demented & 2 & 0.4 \\
\hline Depressed & 13 & 2.7 \\
\hline Depression & 13 & 2.7 \\
\hline Different & 24 & 5.0 \\
\hline Distressed & 0 & 0.0 \\
\hline Disturbed & 1 & 0.2 \\
\hline Dumb & 13 & 2.7 \\
\hline Embarrassed & 2 & 0.4 \\
\hline Flid & 0 & 0.0 \\
\hline Freak & 4 & 0.8 \\
\hline Frustrated & 3 & 0.6 \\
\hline Insane & 17 & 3.5 \\
\hline Isolated & 0 & 0.0 \\
\hline Loneliness & 1 & 0.2 \\
\hline Loony & 0 & 0.0 \\
\hline Mental & 7 & 1.5 \\
\hline Nuts & 3 & 0.6 \\
\hline Problem & 70 & 14.5 \\
\hline Psychiatric & 0 & 0.0 \\
\hline Psycho & 22 & 4.6 \\
\hline Retard & 0 & 0.0 \\
\hline Sad & 30 & 6.2 \\
\hline Schizophrenia & 45 & 9.3 \\
\hline Screw loose & 0 & 0.0 \\
\hline Spastic & 0 & 0.0 \\
\hline Straight jacket & 0 & 0.0 \\
\hline Unpredictable & 1 & 0.2 \\
\hline Violence & 173 & 35.9 \\
\hline Wheel chairs & 0 & 0.0 \\
\hline Total & 482 & 100.0 \\
\hline
\end{tabular}

Food blogs in the sample are most likely to be 'not ableist,' comprising $68 \%$ of blogs that contain 11 counts of ableist terminology or less. Of the $24 \%$ of blogs considered 'ableist' and 'very ableist,' $33 \%$ are attributed to food and consumption, $25 \%$ to non-profits, and $42 \%$ to unaffiliated theory blogs. Specifically, unaffiliated theory-based blogs comprise $60 \%$ of those that qualify only as 'very ableist' (Figure 2). Therefore, of those blogs that were flagged for ableism, food blogs were less likely to engage ableism in any substantial way, while theory blogs unaffiliated with a non-profit organization were much more likely to engage ableism. Recall that coders identified 323 ableist words within the five-year sample from Animal Rights: The Abolitionist Approach alone. Meanwhile, 18 of the 29 food blogs (62\%) contained no 
identifiable ableist words at all. Veganism: A Truth Whose Time Has Come, another unaffiliated theory blog, had the second highest frequency of ableist terms at 68 . When looking at the average of ableist language (the number of keywords identified in a blog in relation to the total number of posts published by the blog within the five-year time frame), we see that non-profit blogs have no significant means of identifiable ableism, three consumption blogs demonstrate significant means, and the unaffiliated theorybased blogs have quite a few significant means (Figure 3). These trends probably reflect the differing goals of food-based and theory-based blogs. Food and consumption blogs prioritize diet, but theory blogs focus on social justice efforts and are thus more likely to engage contentious language. The lack of affiliation with a non-profit organization may be working to reduce accountability and adherence to professional standards that might temper the use of problematic language.

Figure 1. Frequencies by blog. ${ }^{18}$

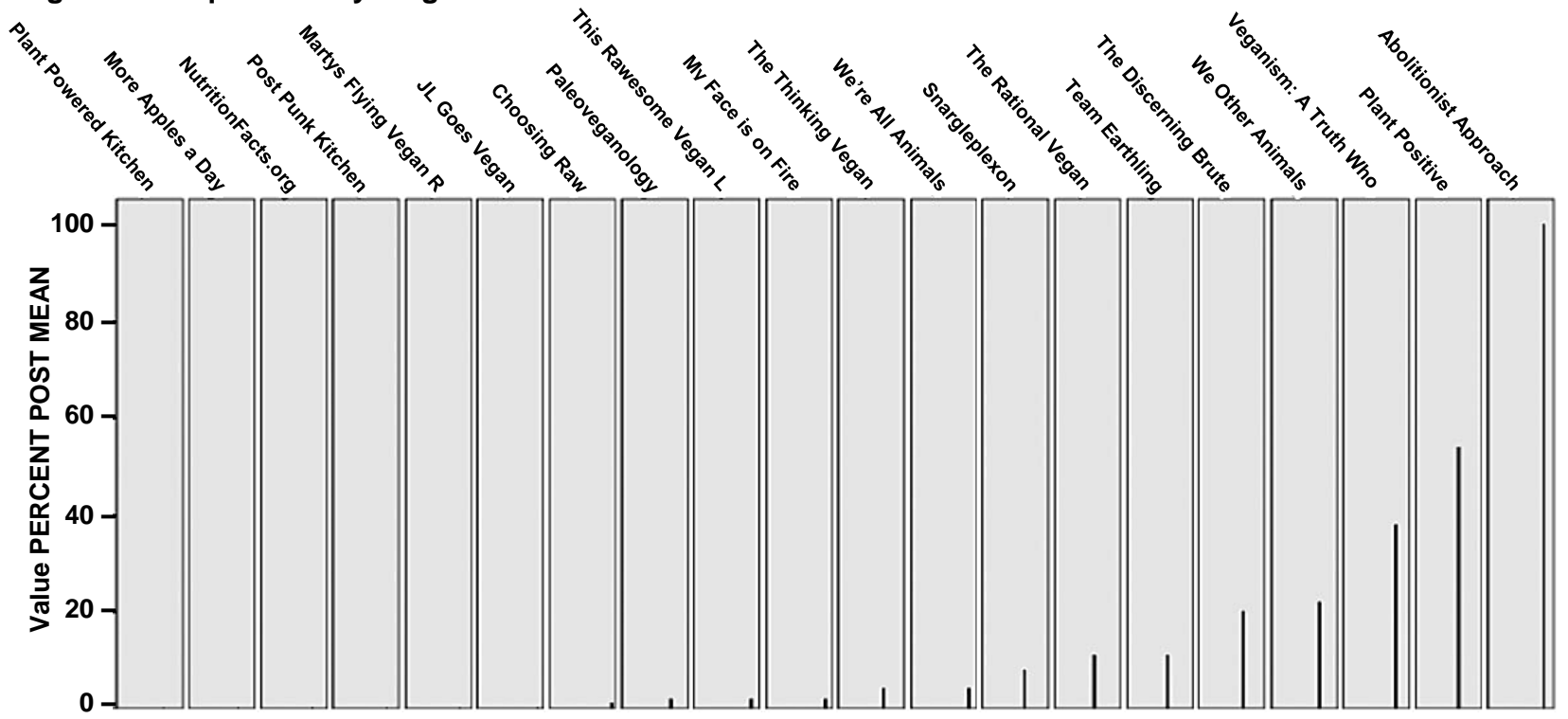

Table 3. Distribution of ableism.

\begin{tabular}{|llcc|}
\hline & & Frequency & Percentage \\
\hline Valid & Not ableist & 38 & 76.0 \\
& Ableist & 7 & 14.0 \\
& Very ableist & 5 & 10.0 \\
& Total & 50 & 100.0 \\
\hline
\end{tabular}

Figure 2. Distribution of ableism by blog type.

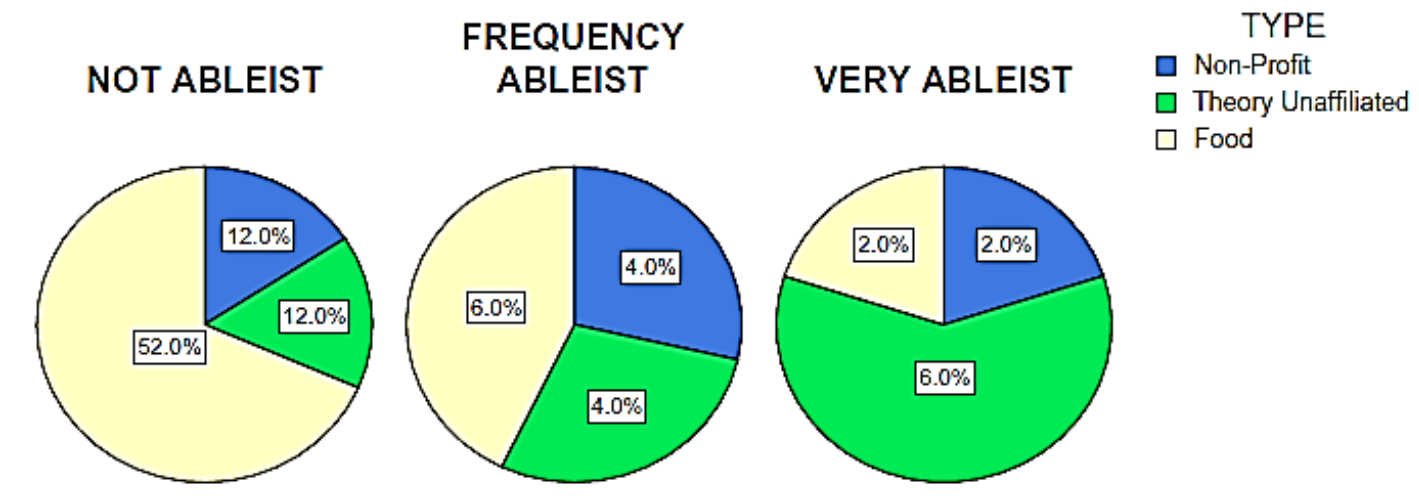


Figure 3. Frequency averages by blog type.

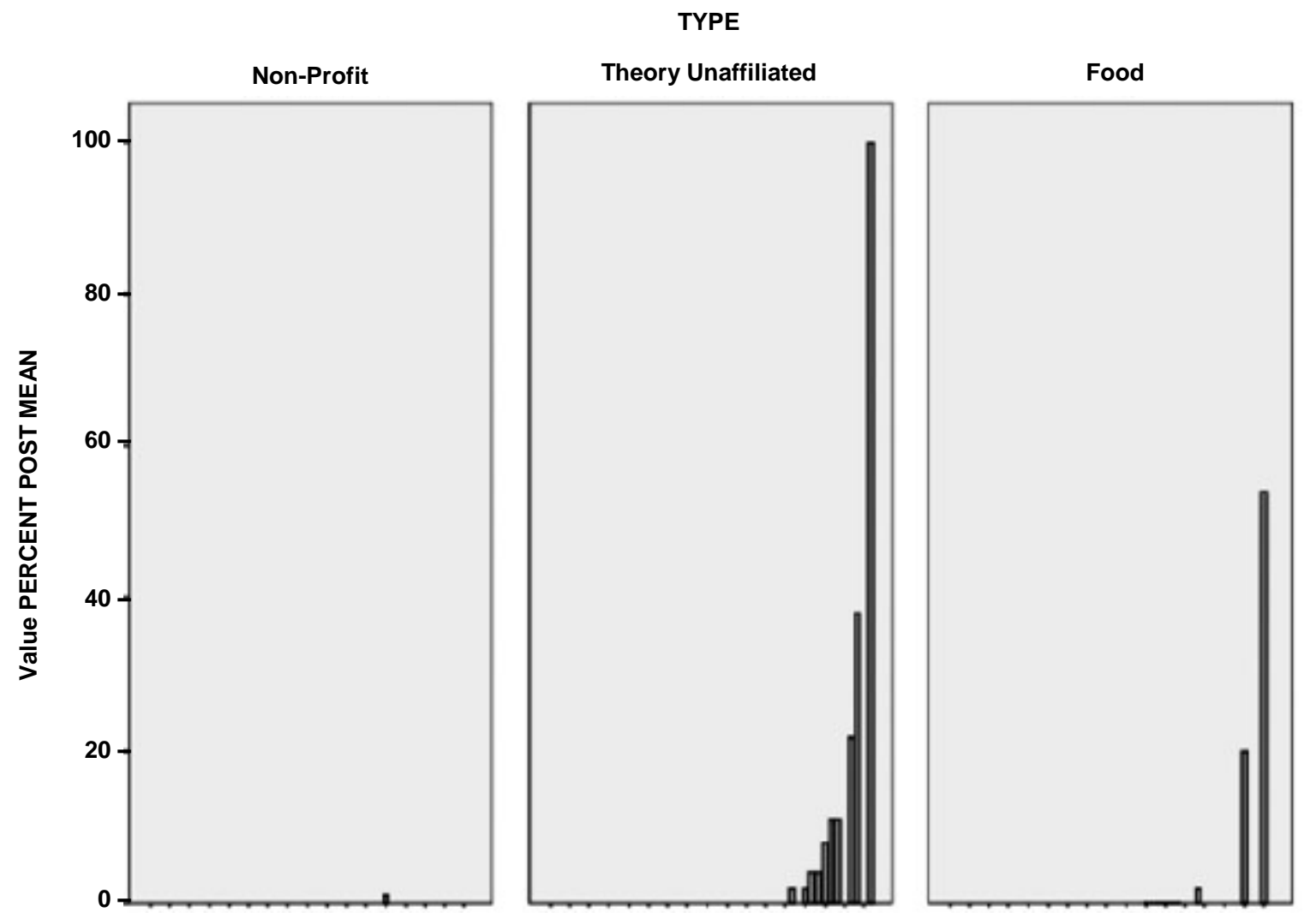

\section{Conclusion}

In the volatile social movement arena, movements and their countermovements struggle over meaning construction. In order to achieve this symbolic power, participants may frame their claims-making in a way that could seek to otherize and demean their opponent. In the case of Nonhuman Animal rights, it seems that, based on our media analyses, the exploitation of Nonhuman Animals has been, to some extent, medicalized as a mental impairment by activists, while collective action on behalf of other animals has also been somewhat medicalized as a mental impairment by its countermovement. Disability is thus politicized as a means to construct the opposition as deviant, misguided, and undesirable. This is particularly evident in theory-based vegan blogs, which were more likely to pull on ableist terminology in claims-making efforts. Newspapers, too, evidenced ableist language, which was somewhat expected given previous research on anti-speciesism in mainstream media.

We conclude that, based on our limited samples, the social problem of mental health stigmatization is applied to frame contestations over Nonhuman Animal exploitation to some extent. For countermovements invested in the protection of large-scale violence against Nonhuman Animals, the discriminatory exploitation of disability may not be especially surprising. Yet countermovements must be careful to avoid engaging in mobilization behaviors that could jeopardize their carefully constructed identity. As Jasper and Poulsen (1993) discovered in their analysis of Nonhuman Animal rights movement/countermovement interactions, activists are especially keen to take advantage of pre-existing countermovement vulnerabilities, but are also on alert for any potential countermovement blunders that could work in their favor. By insinuating that Nonhuman Animal activists are mentally impaired, and 
therefore loathsome or dismissible (thereby implying that people with disabilities are loathsome or dismissible), opponents are cultivating a tactical vulnerability (ableism) that could easily work to their disadvantage.

Social movements, particularly those interested in social equality, should also be mindful of ableism in their own claims-making. It may be tempting for activists reacting to the traumatic knowledge of Nonhuman Animal suffering to question the mental ability of 'hunters,' vivisectors, slaughterhouse workers, farmers, and non-vegans, but activists should be mindful of how these persons are products of socialization processes and structural constraints. These forces affect both people with disabilities and non-disabled persons; and they are constantly reinforced by the powerful institutions of family, media, education, medicine, and religion, thus severely complicating social change efforts.

Social movements draw on existing cultural norms to create resonant frames. As we have seen, these norms might be positive and inclusive (as with the Superbarrio and the Abolitionists), or they might be otherizing and discriminatory. In the case of Nonhuman Animal rights, the culturally normative practice of ableism appears to be utilized by activists to construct meaning and otherize the opposition. But ableism is only one of many prejudices that have seeped into the movement for other animals. PETA, for instance, has been soundly criticized for utilizing sexism in its tactical repertoire (Adams 2000; Deckha 2008; Gaarder 2011; Wrenn 2013). PETA justifies this exploitation as a means of garnering media attention, but an analysis of its outreach efficacy has suggested that the negative attention it receives is not necessarily any better than no attention at all (Mika 2006). A recent study finds that PETA's sexualization approach actually has the opposite of the intended effect, as male observers recognize that female activists are being exploited and are subsequently turned off to the organization's message (Bongiorno, Bain, and Haslam 2013). A movement that utilizes potentially offensive tactics leaves itself vulnerable to discredit. Therefore, social movements may benefit from embracing a reflexivity that seeks to challenge any cultural prejudices that may have been incorporated into their claims-making.

Frames that do not resonate can undermine a movement's credibility, but a good frame must be accessible as well as credible (Ross 2005). If a movement's frame is capitalizing on ableism while alienating demographics with disabilities, this frame is likely to be unsound and could impair the social movement's viability. Effective framing, on the other hand, is flexible and responsive (Snow and CorrigallBrown 2005); if activists and the public were to reject discriminatory claims-making, the social movement should be able to adjust accordingly to reflect these value shifts. Social movements have any number of inclusive and affirmative frames they could alternatively reference. In the case of Nonhuman Animal rights, ableism is hardly necessary given the litany of other themes available. For instance, many activists draw from cruelty frameworks (Munro 2005), while others build on rights rhetoric (Regan 2004b).

It might also be argued that discrimination based on disability is fundamentally incompatible with a movement aimed at ending discrimination based on species. Daniel Salomon (2010) suggests that ableist claims-making in the Nonhuman Animal rights movement effectively otherizes people with disabilities to the movement's detriment: 'Certain sectors of the animal movements alienating a group of people, who do not need to be alienated, is both counterproductive and undermining to the animal liberation strategy' $(2010,67)$. Activists should be wary of ableist claims-making, not only because of its potential to undermine the movement's efficacy, but also because ableism could be a threat to the integrity of a movement founded in values of social justice.

While our results demonstrate some evidence of ableist claims-making on both fronts of the speciesism issue, we conclude with a discussion of several important limitations to this study. First, our newspaper sample looked only at the use of ableist words contained within headlines, not the body of the story. Expanding the sample to explore the use of ableism in the news stories could demonstrate a stronger 
trend in medicalizing activism. Second, some language utilized by Nonhuman Animal rights activists could be considered ableist or non-ableist depending on context. 'Problem' and 'violence,' in particular, were difficult to code because speciesism is so often viewed objectively as a 'problem' that involves 'violence.' In many cases, coder reliability was stressed from the nuance of language. Likewise, the list of ableist words we utilized is not exhaustive. Words such as 'stupid,' 'idiot,' or 'idiotic' would probably increase available evidence for ableist claims-making.

Another shortcoming that surfaced is the difficulty in obtaining frequency percentages, as LexisNexis does not list the number of news sources included in its search and many blogs do not list the number of total posts published. Therefore, some findings cannot be situated in relation to the total amount of information available in our five-year frame. This limited the amount of relevant information we could discern from our data. As an example, our VegNews Daily sample contains a total of 13 ableist words, but because we have no way of knowing how many times this blog was updated between 2009 and 2013, it is impossible to say whether 13 is a relatively large number or not for that blog.

Finally, the distribution of blog types may obscure relevant trends. We drew our blog sample from The Vegan Feed, which includes very few non-profit blogs. None of the blogs in our sample are maintained by very large and influential organizations like PETA or the Humane Society of the United States. The claims-making of major players in the Nonhuman Animal rights space could be especially illuminating. These organizations also tend to engage claims-making directed at other activists, primarily those associated with radical factions (Wrenn 2012). The dialog between large non-profits and smaller grassroots groups could also prove relevant to the exploitation of ability status in claims disputes.

\section{Acknowledgements}

The authors would like to acknowledge the helpful suggestions from anonymous reviewers regarding appropriate disability language as well as the theory of narrative prosthesis.

\section{Disclosure statement}

No potential conflict of interest was reported by the authors.

\section{Notes}

1. Nonhuman Animals is capitalized to indicate their status as an oppressed group.

2. Euphemisms like 'meat' and 'fur' are placed in quotations.

3. Carol J. Adams (2000) first applied this concept to the exploitation of women and Nonhuman Animals.

4. This statement introduced an article covering the story of a woman who supposedly tried to hire a hit man to kill someone wearing Nonhuman Animal hair. While Murdoch suggests later in the piece that the woman was not representative of Nonhuman Animal rights activism ('[...] it's pretty clear that Lowell is unstable and didn't have a super clear grasp of the magnitude of what she was plotting.'), her opening statement with regards to all Nonhuman Animal activists seeks to conflate one person's crime with the behavior of an entire movement.

5. https://www.facebook.com/DSMVanimalrights.

6. http://www.facebook.com/pages/Animal-Rights-Activists-with-Mental-Disorders.

7. On one occasion, she was tried for feeding free-living bears on her property. On another, she had 'interfered' with state conservation offers by standing between the officers and a free-living bear they were attempting to dart.

8. See the work of Gary Francione (1996), who suggests that PETA is not, in fact, a 'rights' organization, but rather a welfare organization that often enacts policies which are either directly or indirectly responsible for Nonhuman Animal suffering and death. 
9. Hoarding is a somewhat of a newly identified mental health concern; its profile and diagnosis is currently debated and it evades clear classification (Mataix-Cols et al. 2010; Saxena 2007).

10. While language has been a major source of discrimination for the disabled community, there has been some pushback. The disabled people's movement has engaged the tactic of 'cripping,' meaning that some seemingly offensive words are actually an intentional attempt to reclaim discriminatory language (Hutcheon and Wolbring 2013). As a reviewer suggested, these political efforts demonstrate that language can be creative and relational. While reclaimed language of this kind was not evidenced in the data, it is important to acknowledge that the power of developing and enforcing language is not one-sided.

11. The search term 'animal terrorist' did not produce any results.

12. One blog, The Academic Abolitionist Vegan, was omitted because it is a blog managed by the primary author and this could allow for bias or a conflict of interest. This left us with a total of 50 blogs.

13. From The Vegan Feed website: http://veganfeed.com/about.php.

14. Some entries from Our Hen House were excluded from the search because they were members only and therefore not meant to be viewed by the general public.

15. Three hundred and nineteen (59\%) of these occurrences are attributed to our outlier blog, Gary Francione's Animal Rights: The Abolitionist Approach. When this outlier is controlled for, the occurrences between newspaper headlines and vegan blogs in our sample are much closer at 229 and 218 respectively. Recall, however, that the datasets are very different in terms of scale, audience, and distribution; newspaper headlines recognized by LexisNexis and blog entries recognized by The Vegan Feed are not especially comparable.

16. Coders utilized the keyword search to determine the presence of our variables. For eight blogs, this was the only means of access to older posts. Without a sitemap or a calendar of updates, tallying the total number of posts from these blogs is not possible.

17. Although it could also have been included in the consumption, food, and nutrition category, VegNews Daily was included in the non-profit category. This decision is based on its identity as an organization with an anti-speciesist focus, but it is not a non-profit.

18. Blogs that contain no ableist words in the sample are omitted from the graph.

\section{References}

Abramson, L., and H. Sackheim. 1977. "A Paradox in Depression: Uncontrollability and Self-blame." Psychological Bulletin 84 (5): 838-851.

Adams, C. 2000. The Sexual Politics of Meat: A Feminist Vegetarian Critical Theory. London, UK: Continuum.

Andrews, K. 2002. "Movement-countermovement Dynamics and the Emergence of New Institutions: The Case of 'White Flight' Schools in Mississippi." Social Forces 80 (3): 911-936.

BBC News India. 2012. "India Textbook on 'Lying, Cheating Meat-eaters' Withdrawn." BBC, November 20. http://www.bbc.co.uk/news/world-asia-india-20405451.

Benford, R. 1993. "Frame Disputes within the Nuclear Disarmament Movement." Social Forces 71 (3): 667-701. 
Benford, R., and D. Snow. 2000. "Framing Processes and Social Movements: An Overview and Assessment." Annual Review of Sociology 26: 611-639.

Blaxter, J. 2009. "As Seen on TV - or Seen off? Towards a Vegan Media Critique." Critical Society 1 (Winter): 7-14.

Bongiorno, R., P. Bain, and N. Haslam. 2013. "When Sex Doesn't Sell: Using Sexualized Images of Women Reduces Support for Ethical Campaigns." PLoS ONE 8 (12): e83311.

Breen, S. 2011. "Fur Nuts Threaten Barnardo." The Sun, October 17.

Cadena-Roa, J. 2002. "Strategic Framing, Emotions, and Superbarrio - Mexico City's Masked Crusader." Mobilization 7 (2): 201-216.

Clemens, E. 1996. "Organizational Form as Frame: Collective Identity and Political Strategy in the American Labor Movement, 1880-1920." In Comparative Perspectives on Social Movements: Political Opportunities, Mobilizing Structures, and Cultural Framings, edited by D. McAdam, J. McCarthy, and M. Zald, 205-226. Cambridge, UK: Cambridge University Press.

Cole, M., and K. Morgan. 2011. "Veganphobia: Derogatory Discourses of Veganism and the Reproduction of Speciesism in UK National Newspapers." The British Journal of Sociology 62 (1): 134153.

Conrad, P. 1992. "Medicalization and Social Control." Annual Review of Sociology 18: 209-232.

Conrad, P. 2007. The Medicalization of Society: On the Transformation of Human Conditions into Treatable Disorders. Baltimore, MD: The Johns Hopkins University Press.

Corrigan, P. 2000. "Mental Health Stigma as Social Attribution: Implications for Research Methods and Attitude Change." Clinical Psychology: Science and Practice 7 (1): 48-67.

Corrigan, P. 2004. "How Stigma Interferes with Mental Health Care." American Psychologist 59 (7): 614625.

Croteau, D., and W. Hoynes. 2003. Media Society: Industries, Images, and Audiences. Thousand Oaks, CA: Pine Forge Press.

Crowell, E. 2010. "Jack Hanna." Northern 26. http://www.northernexpress.com/michigan/article-4591-jack-hanna.html.

Deckha, M. 2008. "Disturbing Images: Peta and the Feminist Ethics of Animal Advocacy." Ethics and the Environment 13 (2): 35-76.

Dennis, R. 1995. "Social Darwinism, Scientific Racism, and the Metaphysics of Race." The Journal of Negro Education 64 (3): 243-252.

Einwohner, R. 2002. "Bringing the Outsiders in: Opponents' Claims and the Construction of Animal Rights Activists' Identity." Mobilization 7 (3): 253-268.

Ellen, B. 2012. "Meat Eaters - You Are Daredevils or Dumb. or Both." The Guardian, January 14. http://www.guardian.co.uk/commentisfree/2012/jan/15/barbara-ellen-meateaters-stupid. 
Ellingson, S. 1995. "Understanding the Dialectic of Discourse and Collective Action: Public Debate and Rioting in Antebellum Cincinnati." American Journal of Sociology 101 (1): 100-144.

Foucault, M. 1965. Madness and Civilization: A History of Insanity in the Age of Reason. New York: Random House Inc.

Francione, G. 1996. Rain without Thunder: The Ideology of the Animal Rights Movement. Philadelphia, PA: Temple University Press.

Francione, G. 2008. Animals as Persons: Essays on the Abolition of Animal Exploitation. New York: Columbia University Press.

Francione, G. 2009. "A Note on Moral Schizophrenia." Animal Rights: The Animal Rights Approach. http://www.abolitionistapproach.com/a-note-on-moral-schizophrenia.

Freeman, C. 2009. "This Little Piggy Went to Press: The American News Media's Construction of Animals in Agriculture." The Communication Review 12 (1): 78-103.

Friedman, R. 2012. "In Gun Debate, a Misguided Focus on Mental Illness." The New York Times, December 17. http://www.nytimes.com/2012/12/18/health/a-misguided-focus-onmental-illness-in-guncontrol-debate.html.

Frost, R., G. Steketee, and A. Williams. 2001. "Hoarding: A Community Health Problem." Health \& Social Care in the Community 8 (4): 229-234.

Gaarder, E. 2011. Women and the Animal Rights Movement. New Brunswick, NJ: Rutgers University Press.

Gamson, W., D. Croteau, W. Hoynes, and T. Sasson. 1992. "Media Images and the Social Construction of Reality." Annual Review of Sociology 18: 373-393.

Gamson, W., and A. Modigliani. 1989. "Media Discourse and Public Opinion on Nuclear Power: A Constructionist Approach." American Journal of Sociology 95 (1): 1-37.

Gilman, S., H. King, R. Porter, G. Rousseau, and E. Showalter. 1993. Hysteria beyond Freud. Berkeley, CA: University of California Press.

Goldstein, K. 2010. "PETA Compares Meat Eaters to Terrorists, Sociopaths." The Huffington Post, March 28. http://www.huffingtonpost.com/2010/01/26/peta-compares-meateaters_n_436939.html.

Grimsted, D. 1998. American Mobbing, 1828-1861: Toward Civil War. New York: Oxford University Press.

Hamshaw, G. 2011. "Kitchen Intuition: Getting Creative with Leftovers, and Accommodating Different Eating Styles." Choosing Raw. http://www.choosingraw.com/kitchen-intuitiongetting-creative-withleftovers-and-accommodating-different-eating-styles/.

Hart, N., N. Grand, and K. Riley. 2006. "Making the Grade: The Gender Gap, ADHD, and the Medicalization of Boyhood." In Medicalized Masculinities, edited by D. Rosenfeld and C. Faircloth, 132165. Philadelphia, PA: Temple University Press.

Hinshaw, S. 2007. The Mark of Shame: Stigma of Mental Illness and an Agenda for Change. New York: Oxford University Press. 
Hutcheon, E. and G. Wolbring. 2013. "'Cripping' Resilience: Contributions from Disability Studies to Resilience Theory." Media/Culture Journal $16 \quad$ (5). http://journal.mediaculture.org.au/index.php/mcjournal/article/viewArticle/697.

Jasper, J., and J. Poulsen. 1993. "Fighting Back: Vulnerabilities, Blunders, and Countermobilization by the Targets in Three Animal Rights Campaigns." Sociological Forum 8 (4): 639-657.

Jones, L. 2009. "Natalie Portman Reinforces Stereotypes about Loony Veggies by 'Equating Meat-eating with Rape'." The Telegraph, October 29.

Joy, M. 2010. Why We Love Dogs, Eat Pigs, and Wear Cows: An Introduction to Carnism. San Francisco, CA: Conari Press.

Link, B., J. Monahan, A. Stueve, and F. Cullen. 1999. "Real in Their Consequences: A Sociological Approach to Understanding the Association between Psychotic Symptoms and Violence." American Sociological Review 64 (2): 316-322.

Mason, M. 2011. "Necessary but Not Sufficient: Revolutionary Ideology and Antislavery Action in the Early Republic." In Contesting Slavery: The Politics of Bondage and Freedom in the New American Nation, edited by J. Hammond and M. Mason, 11-31. Charlottesville, VA: University of Virginia Press.

Mataix-Cols, D., R. Frost, A. Pertusa, L. Clark, S. Saxena, J. Leckman, D. Stein, H. Matsunaga, and S. Wilhelm. 2010. "Hoarding Disorder: A New Diagnosis for DSM-V?" Depression and Anxiety 27 (6): 556572.

Maurer, D. 2002. Vegetarianism: Movement or Moment. Philadelphia, PA: Temple University Press.

Mayes, R., and A. Horwitz. 2005. "DSM-III and the Revolution in the Classification of Mental IIIness." Journal of the History of the Behavioral Sciences 41 (3): 249-267.

McAdam, D. 1994. "Culture and Social Movements." In New Social Movements: From Ideology to Identity, edited by E. Larana, H. Johnston, and J. Gusfield, 36-57. Philadelphia, PA: Temple University Press.

Metzl, J. 2010. The Protest Psychosis: How Schizophrenia Became a Black Disease. Boston, MA: Beacon Press.

Meyer, V. 2001. "The Medicalization of Menopause: Critique and Consequences." International Journal of Health Services 31 (4): 769-792.

Mika, M. 2006. "Framing the Issue: Religion, Secular Ethics and the Case of Animal Rights Mobilization." Social Forces 85 (2): 915-941.

Mitchel, S. 2004. Frances Power Cobbe: Victorian Feminist, Journalist, Reformer. Charlottesville, VA: University of Virginia Press.

Mitchell, D., and S. Snyder. 2000. Narrative Prosthesis: Disability and the Dependencies of Discourse. Ann Arbor, Ml: The University of Michigan Press.

Mitzman, D. 2013. "Where Vegetarianism is an Exotic Illness." BBC News Magazine, January 13. http://www.bbc.co.uk/news/magazine-20970092. 
Morgan, K. and M. Cole. 2011. "The Discursive Representation of Nonhuman Animals in a Culture of Denial." In Human and Other Animals: Critical Perspectives, edited by B. Carter and N. Charles, 112-131. New York: Palgrave MacMillion.

Moszczynski, J. 2012. "N.J. Animal Rights Activist Fighting State's Attempt to Revoke Her Firearms Card." The Star-Ledger, December 9. http://www.nj.com/sussexcounty/index.ssf/2012/12/nj_animal_rights_activist_fighting_states_attempt_to_revoke_her_firearms_card .html.

Mottl, T. 1980. "The Analysis of Countermovements." Social Problems 27 (5): 620-635.

Munro, L. 1999. "Contesting Moral Capital in Campaigns against Animal Liberation." Society and Animals 7 (1): 35-53.

Munro, L. 2005. Confronting Cruelty: Moral Orthodoxy and the Challenge of the Animal Rights Movement. Leiden, NL: Brill Academic Pub.

Murdoch, C. 2012. "Terrible Animal Rights Activist Tries to Hire Hit Man to Kill Someone Wearing Fur." Jezebel, February 22. http://jezebel.com/5887529/terrible-animal-rights-activist-tries-to-hire-hit-man-to-killsomeone-wearing-fur.

Nibert, D. 2002. Animal Rights/Human Rights: Entanglements of Oppression and Liberation. Oxford, UK: Rowman and Littlefield.

Oegema, D., and B. Klandermans. 1994. "Why Social Movement Sympathizers Don't Participate: Erosion and Nonconversion of Support." American Sociological Review 59 (5): 703-722.

Oliver, P., and H. Johnston. 2000. "What a Good Idea! Frames and Ideologies in Social Movement Research." Mobilization 5: 37-54.

Patronek, G. 1999. "Hoarding of Animals: An under-recognized Public Health Problem in a Difficult-tostudy Population." Public Health Reports 114 (1): 81-87.

PETA. 2005. Animal Hoarders: Behavior, Consequences, and Appropriate Official Response. Norfolk, VA: PETA.

PETA. 2010. 'No-kill' Shelters: Hoarding a Secret. Winter: Animal Times. PETA. N.d. '“No-kill' Label Slowly Killing Animals." Issues. http://www.peta.org/issues/nokill-label-slowly-killing-animals.aspx.

Pruitt, S. 2010. "Only Sociopaths Intentionally Hurt Animals: A Professional View." PETA Prime, April 6. http://prime.peta.org/2010/04/only-sociopaths-intentionally-hurt-animalsa-professional-view.

Rachman, S., D. Thordarson, R. Shafran, and S. Woody. 1995. "Perceived Responsibility: Structure and Significance." Behaviour Research and Therapy 33 (7): 779-784.

Reed, E. 1978. Sexism and Science. Atlanta, GA: Pathfinder Press.

Regan, T. n.d. 2004a. Empty Cages: Facing the Challenge of Animal Rights. Oxford, UK: Rowman \& Littlefield Publishers Inc.

Regan, T. 2004b. The Case for Animal Rights. Berkeley, CA: The University of California Press. 
Regan, T. n.d. "Animal Rights \& The Myth of 'Humane' Treatment." Rights \& Writes. http://tomregan.info/essays/animal-rights-the-myth-of-humane-treatment/

Rose, D., G. Thornicroft, V. Pinfold, and A. Kassam. 2007. "250 Labels Used to Stigmatise People with Mental Illness." BMC Health Services Research 7 (97). http://www.biomedcentral.com/1472-6963/7/97.

Ross, R. 2005. "Sweatshop Labor: (Re)Framing Immigration." In Rhyming Hope and History: Activists, Academics, and Social Movement Scholarship, edited by D. Croteau, W. Haynes, and C. Ryan, 176-190. Minneapolis, MN: University of Minnesota Press.

Salomon, D. 2010. "From Marginal Cases to Linked Oppressions: Reframing the Conflict between the Autistic Pride and Animal Rights Movements." Journal for Critical Animal Studies 8 (1/2): 47-72.

Saxena, S. 2007. "Is Compulsive Hoarding a Genetically and Neurobiologically Discrete Syndrome? Implications for Diagnostic Classification." The American Journal of Psychiatry 164 (3): 380-384.

Schulze, B., and M. Angermeyer. 2003. "Subjective Experiences of Stigma. a Focus Group Study of Schizophrenic Patients, Their Relatives and Mental Health Professionals." Social Science \& Medicine 56 (2): 299-312.

Schur, E. 1984. Labeling Women Deviant: Gender, Stigma, and Social Control. Philadelphia, PA: Temple University Press.

Searight, H., and A. McLaren. 1998. "Attention-deficit Hyperactivity Disorder: The Medicalization of Misbehavior." Journal of Clinical Psychology in Medical Settings 5 (4): 467-495.

Shapiro, J. 1994. No Pity: People with Disabilities Forging a New Civil Rights Movement. New York: Three Rivers Press.

Singer, P. 2009. "Speciesism and Moral Status." Metaphilosophy 40 (3-4): 567-581.

Snow, D. and C. Corrigall-Brown. 2005. "Falling on Deaf Ears; Confronting the Prospect of Nonresonant Frames." In Rhyming Hope and History: Activists, Academics, and Social Movement Scholarship, edited by D. Croteau, W. Haynes, and C. Ryan, 176-190. Minneapolis, MN: University of Minnesota Press.

Swan, J. 1995. In Defense of Hunting: Yesterday and Today. New York: HarperCollins Publishers Inc.

Swidler, A. 1995. "Cultural Power and Social Movements." In Social Movements and Culture, edited by H. Johnston and B. Klandermans, 25-40. Minneapolis, MN: University of Minnesota Press.

The Economist. 1995. "People and Animals: Also Part of Creation." The Economist 19, August: 17-19.

Westby, D. 2002. "Strategic Imperative, Ideology, and Frame." Mobilization 7 (3): 287-304.

Winograd, N. 2007. Redemption: The Myth of Pet Overpopulation and the No Kill Revolution in America. Los Angeles, CA: Almaden Books.

Wrenn, C. 2012. "Applying Social Movement Theory to Nonhuman Rights Mobilization." Peace Studies Journal 5 (3): 27-44.

Wrenn, C. 2013. "The Role of Professionalization regarding Female Exploitation in the Nonhuman Animal Rights Movement." Journal of Gender Studies 24 (2): 131-146. 
Wrenn, C. 2015. A Rational Approach to Animal Rights: Extensions in Abolitionist Theory. London, UK: Palgrave Macmillan.

Yadavendu, V. 2001. "Social Construction of Health: Changing Paradigms." Economic and Political Weekly 36 (29): 2784-2795.

Zald, M. 1996. "Culture, Ideology, and Strategic Framing." In Comparative Perspectives on Social Movements: Political Opportunities, Mobilizing Structures, and Cultural Framings, edited by D. McAdam, J. McCarthy, and M. Zald, 261-274. Cambridge, UK: Cambridge University Press. 